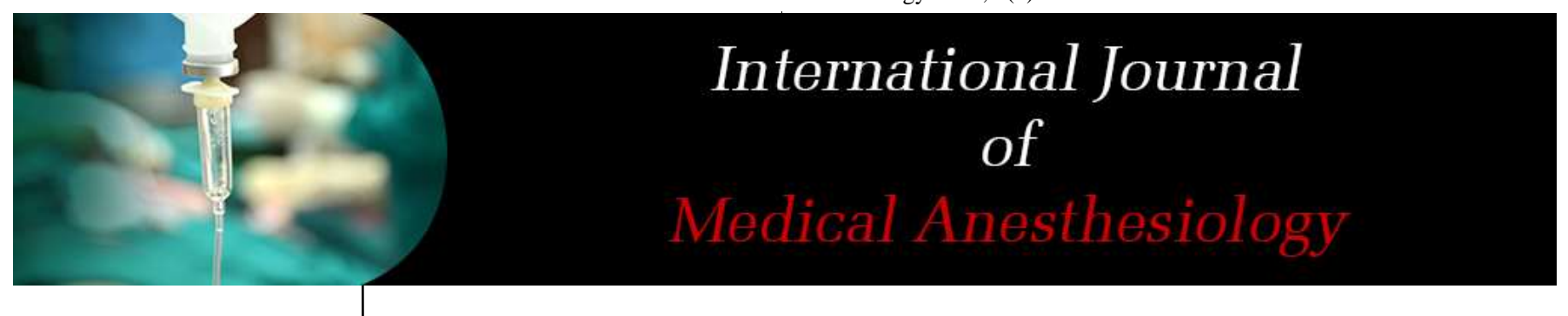

E-ISSN: 2664-3774

P-ISSN: 2664-3766 www.anesthesiologypaper.com IJMA 2021; 4(1): 75-78

Received: $26-10-2020$

Accepted: 05-12-2020

Dr. Kajabanu Y Hugar Senior Resident, Department of Anesthesiology, Gadag Institute of Medical Sciences, Gadag, Karnataka, India

Dr. Vinayak Panchgar Associate Professor, Department of Anesthesiology, Gadag Institute of Medical Sciences, Gadag, Karnataka, India

Corresponding Author: Dr. Vinayak Panchgar Associate Professor, Department of Anesthesiology, Gadag Institute of Medical Sciences, Gadag, Karnataka, India

\section{A comparative study of haemodynamic response during LMA supreme insertion versus endotracheal intubation in paralysed patients during general anaesthesia}

\author{
Dr. Kajabanu Y Hugar and Dr. Vinayak Panchgar
}

DOI: https://doi.org/10.33545/26643766.2021.v4.i1b.197

\begin{abstract}
Introduction: LMA Supreme is a device which has recently been gaining popularly as an aid to airway management. During ETT intubation induces reflex sympathetic adrenal stimulation which is associated with raised levels of plasma catecholamines. This raised catecholamines induce hypertension and tachycardia. These effects should be avoided in patients with hypertension, ischemic heart disease, stenotic valvular heart disease, and raised intracranial tension, LMA Supreme can be used to over come the sympathetic response.

Materials and Methods: 80 patients of either sex, aged 18 to 50 yrs posted for elective surgeries. Randomized to 2 groups $\mathrm{N}=40$ each. We recorded $\mathrm{HR}, \mathrm{SBP}, \mathrm{DBP}, \mathrm{MAP}, \mathrm{ETCO}_{2}, \mathrm{SPO}_{2}$ at $0,1,5,10$ min and post extubation after LMA Supreme insertion, ET tube intubation and ease of insertion, no of attempts and post operative complications.

Results: LMA Supreme airway is a safe and effective mean of maintaining airway. Ease and the simplicity makes the device well tolerated and the pressure response is less than endotracheal intubation. In our study we have observed the ETT intubation had increased haemodynamic responses when compared with LMA-S insertion.

Conclusion: LMA Supreme can be suitable alternative to ETT intubation in elective adult surgeries. LMA-S with its unique design will help to expand Anaesthesiologist efficiency in the management of patients.
\end{abstract}

Keywords: LMA aupreme, hemodynamic responses, tracheal intubations

\section{Introduction}

Airway management is an important aspect during general anaesthesia. So it is the responsibility of anaesthesiologists to secure airway and provide adequate ventilation to anaesthestized patients. So maintaining a patient airway is essential for adequate oxygenation and ventilation. Failure to do even for a brief period of time can be life threatening. The standard method of securing airway during general anaesthesia is endotracheal intubation. This provides effective ventilation and protect against aspiration.

Laryngoscopy and endotracheal intubation induces sympathomimetic adrenal stimulation which is associated with raised levels of plasma catecholamines. The stress responses to laryngoscopy and endotracheal intubation is centrally mediated sympathetic reflex. The stretching of the laryngeal and pharyngeal tissue during laryngoscopy, endotracheal intubation was the major cause of haemodynamic responses. This raised catecholamines induces hypertension and tachycardia. These effects should be avoided in patients with ischemic heart disease, hypertension, stenotic valvular heart disease and raised intracranial tension.

LMA Supreme is a second generation supraglottic airway device. LMA Supreme insertion is simple, atraumatic and does not require laryngoscopy. It is made of PVC and latex free. It has an anatomically shaped airway tube into which a separate drain tube has been in corporated and has a modified inflatable cuff.

Designed to offer higher airway seal pressure around laryngeal opening. This also incorporates an integral bite block and tab for adhesive tape fixation. The firm elliptical and anatomically shaped airway tube facilitates easy insertion, includes patented fins designed to prevent occlusion of airway by the epiglottis. 
Hence purpose of this work is to study and compare LMA Supreme with endotracheal intubation in adult's patients posted for elective surgeries with respect ease of insertion. number of attempts of insertion., Haemodynamic changes like heart rate (HR), systolic blood pressure (SBP), diastolic blood pressure (DBP), mean blood pressure (MBP).Oxygen saturation [Spo2], End tidal carbon dioxide [Etco2].

\section{Materials and Methods}

After institutional ethical committee clearance, The study was conducted in 80patients aged between 18 -50 years undergoing elective surgeries under general anaesthesia with controlled ventilation were selected.

A detailed pre anesthetic check up was done. Informed written consent was taken from patients/ parents/ relatives. Age $<18$ yrs and $>50$ yrs, ASA grade 3 and 4 Patient having any anatomical abnormality of the neck anticipated difficult airway. Upper respiratory tract infection History of Obstructive sleep apnea Obese patients with BMI >26 $\mathrm{kg} / \mathrm{m} 2$ were exluded.

\section{Method}

80 Patients were divided into two groups, 40 patients in each group namely "S" and "E".A detailed medical history, complete physical examination and preoperative investigations was done for all patients. Following arrival into the operation theatre intravenous access is established. Monitors were attached. Premedication with Inj. Ondansetron $0.15 \mathrm{mg} / \mathrm{kg}$, Inj Glycopyrrolate $0.01 \mathrm{mg} / \mathrm{kg}$, Midazolam $0.05 \mathrm{mg} / \mathrm{kg}$, analgesia was be provided with Inj.

Fentanyl 2ug/kg. Baseline values of HR, SBP, DBP, MBP, and SPO2 was recorded.

After pre-oxygenation for 3 minutes, patient was induced with Inj. Propofol $2 \mathrm{mg} / \mathrm{kg}$, was confirmed by loss of eyelash reflex. Patient was relaxed with succinylcholine $1.5 \mathrm{mg} / \mathrm{kg}$. For "S" group patients LMA Supreme of appropriate size was inserted after lubricating the dorsal surface of the device. For "E" group patients the trachea was intubated with an appropriate size endotracheal tube under direct laryngoscopy. The cuff of both devices was inflated and fixed. After connecting to breathing circuit, ventilation was checked.

If it's not possible to insert the airway device or ventilate through it, 2 more attempts of insertion was allowed. If placement had failed after 3 attempts, the patient was intubated with endotracheal tube and this was taken as failed attempt.

After securing the airway, the anesthesia was maintained with oxygen+nitrousoxide+isoflurane+neuromuscular blockade with Inj. Vecuronium bromide $0.05 \mathrm{mg} / \mathrm{kg}$.the following parameters Heart rate $[\mathrm{HR}]$, Systolic blood pressure [SBP], Diastolic blood pressure [DBP], Mean blood pressure [MBP], oxygen saturation [SPO2], End tidal carbon diaxode [ETCO2] recorded at 0, 1, 5, $10 \mathrm{~min}$ of insertion and at the end of surgery after removal of device, Number of insertion of attempts. Ease of insertion will be described according to subjectiveness of single user aseasy, moderate, difficult or impossible were monitored.

\section{Results}

Table 1: Age distribution

\begin{tabular}{|c|c|c|c|c|c|}
\hline \multirow{2}{*}{ Parameters } & \multirow{2}{*}{ LMA-S (N=40) } & \multirow{2}{*}{ ETT Tube $(\mathbf{N}=40)$} & \multicolumn{3}{|c|}{ Unpaired t Test } \\
\cline { 4 - 6 } & & t Value & P Value & Significance \\
\hline age & $32.92 \pm 12.52$ & $34.17 \pm 11.45$ & -0.466 & 0.643 & NS \\
\hline
\end{tabular}

Table 2: Number of insertion attempts

\begin{tabular}{|c|c|c|c|}
\hline Number of insertion Attempts & LMA-S (N=40) & ETT Tube (N=40) & Chi Square Test \\
\hline First & 38 & 40 & $2.05, \mathrm{P}<0.152, \mathrm{NS}$ \\
\hline second & 2 & 0 & $2.05, \mathrm{P}<0.152, \mathrm{NS}$ \\
\hline Third & 0 & 0 & \\
\hline Abandoned & 0 & 0 & \\
\hline
\end{tabular}

In the LMA Supreme group, LMA insertion was placed correctly in the first attempt in 38 patients and was placed correctly in 2 patients. In the ETT group, ETT intubation was done in first attempt in 40 patients. In both the groups, the number of attempts were statistically comparable and derived $\mathrm{p}$ value $<0.152$ which is not significant.

Table 3: Ease of insertion

\begin{tabular}{|c|c|c|c|}
\hline Ease of Insertion Attempts & LMA-S (N=40) & ETT Tube (N=40) & Chi Square Test \\
\hline Easy & 34 & 30 & $1.25 . \mathrm{P}<0.264, \mathrm{NS}$ \\
\hline M Difficult & 6 & 7 & $0.092, \mathrm{P}<0.762, \mathrm{NS}$ \\
\hline Difficult & 0 & 3 & $3.117, \mathrm{P}<0.07, \mathrm{NS}$ \\
\hline Impossible & 0 & 0 & \\
\hline
\end{tabular}

In both groups the ease of insertion is statistically comparable and $\mathrm{p}$ value derived which is not significant.
Insertion of LMA $\mathrm{S}$ was comparatively easy when compared to ETT group.

Table 4: Heart rate comparision

\begin{tabular}{|c|c|c|c|c|c|}
\hline \multirow{2}{*}{ HR } & \multirow{2}{*}{ LMA-S $(\mathbf{N}=\mathbf{4 0})$} & \multirow{2}{*}{ ETT Tube $(\mathbf{N}=\mathbf{4 0})$} & \multicolumn{3}{|c|}{ Unpaired t Test } \\
\cline { 4 - 6 } & & & t Value & P Value & Significance \\
\hline Basal & $87.1 \pm 9.51$ & $87.65 \pm 8.61$ & -0.271 & 0.787 & NS \\
\hline 1 Min & $85.9 \pm 9.21$ & $93.85 \pm 11.07$ & -3.491 & 0.001 & HS \\
\hline 5 Min & $83.4 \pm 9.39$ & $96.85 \pm 12.06$ & -5.565 & 0.000 & HS \\
\hline
\end{tabular}




\begin{tabular}{|l|c|c|c|c|c|}
\hline 10 Min & $81.35 \pm 8.73$ & $99.55 \pm 13.04$ & -7.337 & 0.000 & HS \\
\hline END & $82.45 \pm 9.21$ & $100.25 \pm 9.86$ & -8.270 & 0.000 & HS \\
\hline NS=Not Significant, HS= Highly Significant \\
र
\end{tabular}

Comparsion of heart rate in both the groups showed the following changes.

The heart rate was compared from baseline $0,1,5,10$ and post extubation.in the both groups the baseline heart rate was comparable statiscally i.e 87.1 \pm 9.51 and $87.65 \pm$
8.61 in ETT group with $\mathrm{p}$ value $=0.787$ which was not significant. After insertion of LMA S and ETT, the heart rate was significantly higher in ETT group with $p$ value derived which was significant.

Table 5: Mean blood pressure comparision

\begin{tabular}{|c|c|c|c|c|c|}
\hline \multirow{2}{*}{ MBP } & \multirow{2}{*}{ LMA-S $(\mathbf{N}=\mathbf{4 0})$} & \multirow{2}{*}{ ETT Tube $(\mathbf{N}=\mathbf{4 0})$} & \multicolumn{3}{|c|}{ Unpaired t Test } \\
\cline { 4 - 6 } & & t Value & P Value & Significance \\
\hline Basal & $92.83 \pm 9.58$ & $91.03 \pm 8.0$ & 0.912 & 0.365 & NS \\
\hline 1 Min & $90.03 \pm 9.72$ & $98.8 \pm 7.21$ & -4.463 & 0.000 & HS \\
\hline 5 Min & $86.7 \pm 9.76$ & $101.67 \pm 7.08$ & -7.847 & 0.000 & HS \\
\hline 10 Min & $85.14 \pm 9.48$ & $104.11 \pm 6.16$ & -10.605 & 0.000 & HS \\
\hline END & $86.29 \pm 9.56$ & $105.08 \pm 5.51$ & -10.769 & 0.000 & HS \\
\hline NS=Not significant, HS= Highly significat
\end{tabular}

The MAP was compared in the both group at baseline with $\mathrm{p}$ value which was not significant. But MAP at 1, 5, 10 and post extubation showed significant increase in ETT group with $\mathrm{p}$ value derived which showed significant.

Table 6: $\mathrm{ETCO}_{2}$ Chart

\begin{tabular}{|c|c|c|c|c|c|}
\hline \multirow{2}{*}{ ET CO} & \multirow{2}{*}{ LMA-S $(\mathbf{N}=\mathbf{4 0})$} & \multirow{2}{*}{ ETT Tube $(\mathbf{N}=\mathbf{4 0})$} & \multicolumn{3}{|c|}{ Unpaired t Test } \\
\cline { 4 - 6 } & & & t-Value & P-Value & Significance \\
\hline Basal & $35.15 \pm 0.36$ & $35.2 \pm 0.45$ & -1.36 & 0.176 & NS \\
\hline 1 Min & $35.1 \pm 0.30$ & $35.12 \pm 0.43$ & -1.778 & 0.079 & NS \\
\hline $5 \mathrm{Min}$ & $35.12 \pm 0.33$ & $35.13 \pm 0.42$ & -1.172 & 0.245 & NS \\
\hline 10 Min & $35.15 \pm 0.36$ & $35.15 \pm 0.36$ & 0.582 & 0.562 & NS \\
\hline END & $35.15 \pm 0.31$ & $35.13 \pm 0.50$ & -1.272 & 0.207 & NS \\
\hline NS=Not significant
\end{tabular}

The End Tidal $\mathrm{CO}_{2}$ concentration was recorded in the both groups the both groups were statistically compared at basal 1, 5,10 and post extubation which was not significant.

\section{Discussion}

Dr Brain was first person to introduce the supraglottic airway device. The wide spread use of supraglottic airway has revolutionized in clinical practice. The laryngeal mask airway has been shown to be effective means of securing a airway during elective surgeries. Its insertion does not require penetration of larynx, there by making the placement less stimulating than endotracheal tube intubation.

There are several adavantages of using LMA Supreme mainly the ease of insertion, minimal cardiovascular stimulation at insertion and minimal use of muscle relaxation.

Both the groups were comparable and there was no statiscally significant difference with regards to mean age, sex, mallampati grading.

In our study, number of attempts and ease of inertion were compared. There was no significant difference we found that LMA Supreme was easily inserted in 34 patients and required lesser skill than ETT. This study was comparable by shashank chitanoor et al. in which also shows insertion of LMA Supreme was easy.

Factors affecting the ease of insertion of LMA Supreme also includes the methods of insertion by classical method as described by Dr. Brain by complete deflation of the mask. Cases of difficulty with LMA Supreme is due to wrong choice LMA size, difficulty in maneuvering through posterior curvature of pharynx.

In our study, we observed the haemodynamic changes like HR, SBP, DBP and MAP after LMA Supreme insertion and
ETT intubation. We found that increase in HR, SBP, DBP, MAP were significantly lower in LMA Supreme. We also noted that all haemodynamic parameters were significantly higher in ETT group. So minimal haemodynamic changes with LMA Supreme is clinically important in patients with hypertension, ischemic heart disease, stenotic valvular heart disease and raised intracranial pressure.

The study conducted by Balasubramanarian S, Menaha R et al. showed the haemodynamic changes was significantly lower in LMA Supreme group. This was comparable to our study with regards to haemodynamic changes.

The study conducted by Sara.R.Barreira, Camila machado Souza concluded that LMA Supreme is a safe airway device with a advantage of attenuating haemodynamic response during its insertion and reducing the incidence of sore throat and dysphagia in postoperative period. This was also comparable to our study with regards to haemodynamic change.

Respiratory complications in the form of laryngospasm, bronchospasm during emergence and post operative complications like sore throat, cough are major concerns while choosing device for airway management. In our study we found 17 patients complained of cough and 8 patients complained of sore throat in ETT group and none were in LMA Supreme group.

The study conducted by Reza safaeian, Valiollah Hassini et al. noted sorethroat in $44 \%$ and cough in $7 \%$ in ETT group. Our results were similar to our studies. 


\section{Conclusion}

We conclude that LMA Supreme and ETT are suitable for routine use during maintenance of anaesthesia. But LMA Supreme is easy to inert, successful insertion without haemodynamic changes.

\section{References}

1. Sara Barreira R. Camila Machada Souza, et al. Prospective randomized clinical trial of laryngeal mask airway supreme used in patients undergoing general anaesthesia. Revistabrasileira de anestesiologia 2013, 63.

2. Naveed Tahir Siddique, Fazal Hameed Khan, et al. Haemodynamic response to tracheal intubation via intubating laryngeal mask airway verse direct laryngoscope tracheal intubation 2007, 57.

3. Cook TM, Galwad JJ, et al. Evaluation of the LMA Supreme in 100 paralysed patients. Wiley online library 2009, 64.

4. Dr. Sayyed Altaf Bulchari, Dr Imtiaz Nagashet et al. Pressor response and intra ocular pressure changes following insertion of laryngeal mask airway, comparsion with tracheal tube insertion IJA 2003;47(6):473-475.

5. Hoston T, Gurkan Y et al. A new supraglottic airway device-LMA supreme with LMA proseal. Wiley online library 2009;53(7):852-857.

6. Ferzon DZ, Chil Zambare S, Brown D. The effectiveness of LMA supreme in patients with normal and difficult to manage airway. Anaesthesiology 2007, 107.

7. Stauffer JL, Olson DE, et al. Complications and consequence of endotracheal intubation and tracheotomy. A M J Med 1981, 70.

8. Timmeranna A, Cremer S, et al. Prospective clinical and fiberoptic evaluation of the supreme laryngeal mask airway. Anesthesiolgy 2009, 110-262.

9. Ali A, Cantur S, et al. Comparsion of the laryngeal mask airway supreme and laryngeal mask airway classic in adults. Eur J Anaesthesiol 2009;26:1010.

10. Van Zundert A, Brimcombe J. The Lma Supreme-Pilot Study. Anaesthesia 2008;63(2):209-210.

11. Tham HM, Tan SM, et al. A comparsion of the supreme laryngeal mask airway with the proseallma in anaesthetized paralysed adult patients; a randomized cross over study. J Aanesth 2010;57(70):672-678.

12. Shribman AJ, Smith G, et al. Cardiovascular and catecholamines responses to larynoscopy with and without tracheal intubation. Br J Anaesth 1987;59:2959.

13. Hassan HG, Sharkawy EL, et al. Haemodynamic and catecholamine responses to laryngoscopy with and without endotracheal intubation. Acta AnesthesiolSc and 1991;35:442-447.

14. Oczenski W, Krenn $\mathrm{H}$, et al. Heamodynamic and catecholamines stress responses to insertion of tecombitube, laryngeal mask airway or tracheal intubation. Anesth Analg 1999;88:1389-1394.

15. Russel WJ, Morris RG, et al. Changes in plasma catecholamines concentration during endotracheal intubation. Br J Anaesth 1981;53:837-839.

16. Masoomeh T, Mohammed A, et al. Haemodynamic changes occurring with tracheal intubation by direct laryngoscopy compared with intubating mask airway in adults: a random comparsion trail. Egypt $\mathbf{J}$ Anaesth 2013;29:29:103-107.

17. Stauffer JL, Olson DE, et al. Complications and consequences of endotracheal intubation and tracheotomy. Am J Med 1981;70:65-76.

18. Braude $\mathrm{N}$, et al. The preessor response and laryngeal mask insertion. A comparison with tracheal intubation. Anaesthesia 1989;44:551-4.

19. Reinhart DJ. Comparsion of effects of placement of the laryngeal mask airway vs endotracheal tube on cardiovascular response. Anesthesiology 1993;79:A1155.

20. Fujji Y, Toyooka H. Circulatory responses to laryngeal mask airway insertion or tracheal intubation in normotensive and hypertensive patients. Can J Anaesth 1995;42:32-6.

21. Brimacombe J. The advantages of the LMA over the tracheal tube or face mask: metaanalysis. Can J Anaesth 1995;42:1017-1023. 